\title{
Crisis Communication about Nuclear Accidents with Psychological Approaches
}

\author{
Yanran Yang, Lina Jin, Jinbin Li, Chao Fang* \\ Institute of Nuclear and New Energy Technology, Collaborative Innovation, Center of Advanced Nuclear Energy \\ Technology, Key Laboratory of Advanced, Reactor Engineering and Safety of Ministry of Education, Tsinghua, \\ University, Beijing 100084, China
}

Received 26 July 2015

Accepted 18 August 2015

\begin{abstract}
Different from other natural disasters and health emergencies, nuclear accident is a kind of special crisis of organizational crises, which tends to generate public and media interests and criticism more easily. In this paper, we reviewed literatures on risk and crisis communication and analyzed the cases of risk and crisis communication after three famous nuclear accidents (Chernobyl, Three Mile Island and Fukushima) and studied the public risk and crisis communication after these accidents with psychological methods, including (1) discussing the source of nuclear panic with needs theory and cognitive theory and (2) studying the irrational behaviors in nuclear accidents with psychoanalytic theory. After the above analysis, some methods of public risk and crisis communication about nuclear accidents are given. Furthermore, it shows that new media such as Wechat and Microblog play a very important role in this process.
\end{abstract}

Keywords: Risk Communication, Nuclear Accidents, Needs Theory, New Media

\section{Introduction}

Risk and crisis communication is of great essence to public affairs. When health emergencies, natural disasters or other big emergencies happen, effective risk and crisis communication can help to reduce the fears and panic among public and inform the mass with necessary solutions like evacuation recommendation to protect the public from further damage. After the SARS and HINI, Chinese government has formed a rather mature and complete working system of solving the health emergencies including the information disclosure of the outbreak of serious infectious diseases on website, which is significant for the social stability.

But until now, Chinese government lacks welldeveloped risk and crisis communication methods about nuclear accident because there was no terrible nuclear accident yet in China so this work has not been on the agenda (Chen, 2012). However, as the biggest country of developing nuclear energy in the world $(50 \%$ nuclear power plants under construction in the world are in China until 2014), the related risk and crisis

*Corresponding author: fangchao@tsinghua.edu.cn communication about nuclear accident should not be neglected by the government and academic (Dinget al. 2014, Covello et al. 2001). On the other hand, different from the natural disasters and health emergencies, the nuclear accident is a kind of special crisis of organizational crises, which tends to generate public and media interest and criticism more easily. If not being handled appropriately, one failure of crisis communication after nuclear accident will certainly affect public's confidence in the organization and further restrict the development of nuclear energy. Therefore, an effective working model for the risk and crisis communication about nuclear accident should be built in China with taking precautions, especially after Fukushima nuclear accident.

In this paper, we reviewed the cases of risk and crisis communication after three famous nuclear accident (Chernobyl, Three Mile Island and Fukushima) and studied the public risk and crisis communication after nuclear accident with psychological methods, including (1) discussing the source of nuclear panic with needs theory and cognitive theory and (2) studying the 
irrational behaviors in nuclear accidents with psychoanalytic theory. After the above analysis, some methods of public risk and crisis communication about nuclear accident are given in the final.

\section{Literature Review and analysis on Crisis Communication after Nuclear Accidents}

\subsection{Researches on risk and crisis communication after nuclear accidents}

For years, risk and crisis communication after nuclear accidents have attracted a lot of academic attention from various fields, communication, public administration, and psychology, etc. Especially after the three most famous accidents, Chernobyl, Three Mile Island and the Fukushima accidents, scholars spent a lot of efforts on analyzing the communicational behavior of mass media, utility companies, local governments and central government officials, trying to figure out the whole picture of information transmission after the great accidents. Harry Otway and other four scholars (1988) did a research on risk communication in Europe after Chernobyl using a media analysis of seven countries, analyzing their media coverage of the Chernobyl emergency to identify common communication problems after this crisis. Donald J. Zeigler and James Johnson (1989) analyze the information planning after Chernobyl and Three Mile Island and concludes that informational context of an accident will not be the main determiner of human behavior in future nuclear emergencies. Rama Hoetzlein (2012) drew an information map for the visual communication after the Fukushima accidents, to providing more vivid and obvious information to lay people. In Cassandra Koerner 's research (2014), she studies how media coverage of accidents at Chernobyl, Three Mile Island, and Fukushima overwhelmed scientific claims of nuclear safety and security during the production process, trying to bridge the information gap between scientists, the public, and policymakers, by analyzing the titles of newspaper coverage. These researches all use the text material or other media coverage material to analyze the effect of such crisis communication and provide a better method based on their findings.

Other researches analyzes the different perception of risks of lay people and experts in order to provide better and more specific information in later crisis communication. In Skarlatidou, Cheng and Haklay's research (2012), they identify that communicating risks is a complex task as there may be significant differences between the risks perceptions of experts and the public. Other similar researches did by Tanja Perko and other fellow scholars $(2012,2014)$ indicated the nuclear risk communications in different countries and figure out the difference knowledge and risk perception of experts and lay people, providing a better way to inform the public.

All the researches mentioned above, focus on the nuclear risk and crisis communication. Those focused on the crisis communication after the accidents, mainly use the media coverage material after a specific accident as the sample. By analyzing their communicational influence, they try to build a more effective way to inform the public after a nuclear power plant accident. While the risk communication in normal days are not designed for one specific nuclear emergency but for the public acceptance of nuclear. The risk communication of nuclear power plant, nuclear waste issue and even nuclear industry itself are aimed at a better scientific education on nuclear and radiation. A good risk communication during normal days can enable lay people to better understand the concept of radiation and how to behave against a nuclear emergency, which may make it easier for the crisis communication after the accident.

Therefore, the risk and crisis communication after the nuclear accident have two aims in total. On the one hand, correct information about the accident should be disclosed to the public to calm down the public and relieve the public panic also evacuation command should be directly sent to the people within the evacuation scope - that is the short-term aim of crisis communication after an emergency. On the other hand, a nuclear power plant accident may alter the public attitude towards nuclear industry. American people's attitudes after TMI and Japanese people's attitudes after Fukushima are typical examples of such attitudes shift. Under such circumstances, crisis communication after nuclear accident has to have a long-term aim, which is reestablish the public trust and acceptance of nuclear industry. As Donald J. Zeigler and James Johnson (1989) give it in their study, nuclear risk is not only the consequences of a nuclear accident but also the probabilities of next nuclear accident. 


\subsection{The case of Chernobyl nuclear accident}

On 26 April 1986, an explosion happened at the Chernobyl Nuclear Power Plant, which was under the jurisdiction of the USSR at that time. This accident was considered as the worst nuclear accident up till now and was evaluated as a level 7 event according to the International Nuclear Event Scale. However, the local government of the city near the plant, Pripyat, did not inform the residents at the very beginning after the explosion happened. People of the USSR first heard this news from TV news 2 days later, on 28 April. There was a 20 second announcement saying that there had been an accident at the Chernobyl Plant and one of the nuclear reactors was damaged. Reasons, casualties, effects and radiation levels were said being investigated in this short announcement. Before this announcement, it is the Swedish detective result that first found the airborne radioactivity which indicating a nuclear accident happened. Only after that, did the USSR government admitted the nuclear accident. Therefore, the USSR government went against the Time First principle in risk communication by concealing the truth to both the domestic citizens and the international neighbors (Otway, Harry. et al.1988).

As for the countries in the neighborhood of Chernobyl, most of the authorities in Europe that are responsible for risk management of radiation emergencies did not anticipate this accident to be so severe. The emergency plans they set before could not satisfy the need of risk communication after Chernobyl accident. Many countries encountered the problem that they even did not have clear information about what was happening in their own countries. The quantitative information provided by monitoring stations was different within the same countries due to the inconsistent units they used. Besides the confusion caused by radiation report, the special information telephones were so overloaded by the calls that the callers could not get through. One country in Europe even published a wrong number of the information telephones. As a result people with special needs and questions could not got the right information they want, which leads to the doubt of the credibility of the government and in turn made the risk communication even more difficult.

\subsection{The case of Three Mile Island nuclear accident}

On 28 March 1979, several water pumps in the nuclear plant of Three Mile Island stopped working around 4 a.m. The breakdown of water pumps later made the core become overheat and the fuels began to melt. At around 7 o' clock, the station manager Gary Miller announced that a general emergency had happened and it might cause radiological results and informed the local government. In the morning of that day, the Nuclear Regulatory Commission (NRC) was called to help to deal with the accident. Later around 10 o' clock, the lieutenant governor of Pennsylvania State, William Scranton III held a press conference. He said that according to the Metropolitan Edison Company, there had been an incident at Three Mile Island Unit 2 and everything was under control and there was no danger to public health and safety with only a small radiation to the environment. During the press conference, the officials did not anticipate a need to evacuate. Then on 29 March, the Met Ed held their first press conference, Jack Herbein and Walter Creitz shared some new information about the degree of radiation, which had some conflicts with the information said in the press conference before. Then distrust from media had been accumulated. Even worse, Jack Herbein said in the press conference on 30 March that he did not know why they needed to tell each and everything they do to the press.

The communication became better and smoother after the Harold Denton's coming, the personal advisor of President Jimmy Carter. After he came to Harrisburg, they held a joint press conference where the Governor Thornburg and Harold Denton tried to ease public fears. Later on 1 April, President Jimmy Carter and his wife came to pay a personal visit to the Three Mile Island and then gave a speech to public. The end of this accident was marked by a press conference held by Governor Thornburg on 6 April. He held this conference at the site of Three Mile Island plant and said that it would be the last televised address. During the whole process of risk communication, lots of press conferences were used to deliver information and ease public fears. Also, a 24-hour citizen's information center was set up to answer people's questions. Though some doubt were cast on the Metropolitan Edison Company, most people kept calm attitude during the whole process even when some of them were being 
evacuated, which showed the efficiency of risk communication of the government.

\subsection{The case of Fukushima nuclear accident}

On 11 March 2011, a great earthquake of 9.0 magnitude happened in the afternoon. Then a serious of tsunamis struck the Fukushima coast, causing the Fukushima Daiichi reactors to shut down. At the night of 11 March, Japanese government announced an evacuation order to those who lived within a radius of 3 kilometers from the Fukushima I station. The next day, there was a hydrogen gas explosion in the unit 1 at 15:36, which led to significant radiation releases. After the explosion, the first national press conference was held at around 17:48 in Tokyo. Nuclear Safety Commission held the conference and the Chief Cabinet Secretary Yukio Edano spoke on behalf of the government. He told the public about the existence of explosion and admitted that the causes were still under investigation. In his speech, he gave an evacuation order to the residents who lived with a radius of 3 kilometers from the Fukushima II station. He asked the public to keep calm and avoid going out and do not listen to or spread rumors. Though this press conference provided some basic information about what had happened, the whole risk communication process of this Fukushima Daiichi accident dissatisfied most Japanese people.

There were a lot of complaints about the delays in releasing radiation data and other important information. The Japanese central government as well as Tokyo Electric Power Company (TEPCO) did not cooperate well on the risk communication that they even provided contradictory information to public. Furthermore, the conflicts between the central government and TEPCO built up an information block that they did not do their utmost to share and utilize the information. These conflicts left a negative impression on the public so that they trusted neither of them. This collapse of trust directly led to the mass objection towards nuclear energy after the Fukushima accident.

\subsection{Analysis of communication methods after three nuclear accidents}

All the risk communication mentioned above shared some flaws in information releasing, public communication and cooperation between government and nuclear plant runners.
Harry Otway and other four scholars (1988) once claimed in their paper in 1988 that modern governments can communicate effectively with the public only through the channel of mass media, especially in emergencies where people must be informed immediately of the developments of the accidents and guided to behave correctly under such circumstances (3). However, as the development of social media and other new media channels, it is much more difficult for government to inform citizens the correct information through mass media. Modern governments have to be aware of noises of misinformation, rumors and other distractions during crisis communication nowadays. In the new environment of crisis communication, there are three questions that should be defined before the communication - what is the correct information, what is the information that citizens need and want to know, and what is the best way to transmit such information.

As Hoetzlein (2012) points out, our primary source for information in times of emergency is the news media. Yet, due to physical circumstances resulting from the crisis, information could be scarce or unreliable. One of the most controversial aspects of accidents is the confusing information on the one hand and a lack of information on the other, which should be responsible for accentuating public perceptions of risk and aggravating efforts in crisis managements (Donald Zeigler \& Johnson, 1989). Natural disaster, such as floodwaters, approaching storms, earthquakes are phenomena that could be gauged by direct sensory inspection. Unlike these disasters, nuclear disaster makes it inaccessible for news media and public to get the primary sources of information without the help from technical experts who can read and interpret instrument panels and computer displays. Thus, after nuclear disaster, secondary sources of information replace primary ones. That could probably explain why it is so important and urgent for government and utility company to give the correct information right after the accident to public, for otherwise citizens may think they are already affected without even noticing or feeling the radiation. However, due to the complexity of nuclear accident, it is hard to get the "correct" information in the first place, especially when the utility companies conceal some information. Such problems can be easily identified in the three cases. The governments and nuclear plant runners either delayed the release of information or gave the wrong one, which all led to the 
doubt from public and collapse of public trust. Therefore, a very basic requirement for risk and crisis communication after the nuclear accidents must be the publication of correct information (Foa et al. 1986).

After knowing what kind of information we have at hand, it is also very important to know what the public needs to know. For nuclear incidents change citizen perceptions toward the safety of nuclear power generation worldwide and may cause sharp declines in the number of individuals who support the development in this field (Cassandra Koerner, 2012). On determining what should be passed to citizens, government should take the public acceptance and perception of risks into consideration, which calls for more researches before the accidents, like what Tanja Perko and other scholars have done. Also, by doing psychoanalytic researches of public, it is also possible to know what is their urgent need after an accident, which will be further discussed in this paper.

Last but not least, via what channels and in what forms to transmit the information are also big problems for crisis communication. In different times, choices have to be made according to its social circumstances. In the time of Three Mile Island and Chernobyl, special telephone line served as the most efficient way for normal people to solve their problems. When it came to the time of Fukushima, website and SNS (Social Networking System) became the most convenient way that normal people rely on to get the specific answer. Thus, these channels for mass communication should be pay attention to as well. This field has already attracted a lot of academic attention to analyze the communicational effects of different methods. This paper will also shed a light on the communicational effect of social media in China.

\section{The Analysis of Public Nuclear Panic with Psychological Method}

\subsection{The analysis of public nuclear panic with needs theory and cognitive theory}

The cause of public nuclear panic is important in risk communication because it shows what should be communicated with public. The Maslow's needs theory (Maslow, 1943) could give us the answer. In this theory, human motivations are divided into five aspects: physiological, safety, belongingness and love, esteem, and self-actualization (Gerriget al. 2007). These five levels are often described like a pyramid, with fundamental needs at the bottom and self-actualization at the top (Fig.1). Physiological needs including food, water, house and so on, are the fundamental needs in daily life and these basic needs play dominant roles and once it cannot be satisfied, a strong motivation will be aroused to fulfill the demands. Safety needs are also essential needs for human beings, which mean that people prefer the world to be safe, predictable, ordered and organized, while all unexpected and dangerous events would bring panic to public. In this sense, both of physiological needs and safety needs should be viewed as fundamental needs and motivations for human beings.

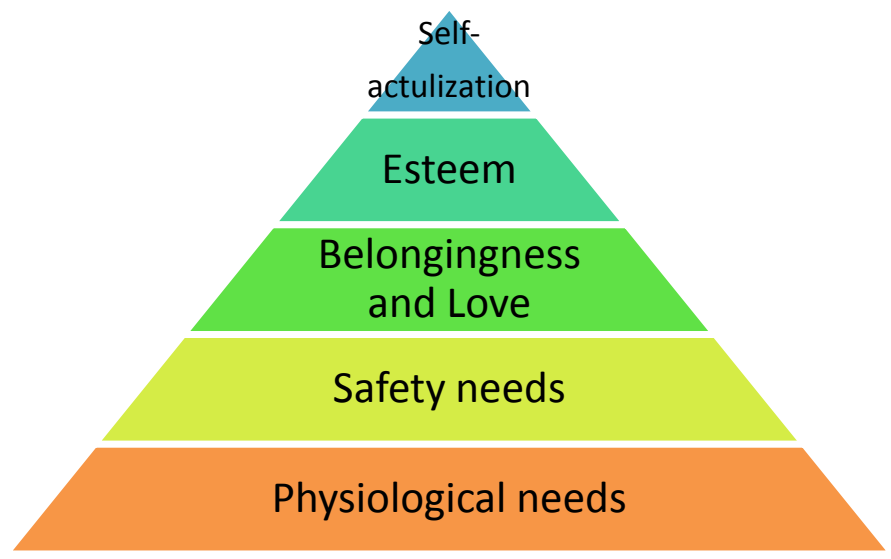

Fig.1. Maslow's Hierarchy of Needs

With this theory, the public panic after nuclear accident originates from the destroying of physiological and safety needs of "pyramid of hierarchy". When nuclear accident happened and radioactive substance release, the radioactive substance could affect the safety of food, air and water in some ways and making public worry about the basic living. As mentioned above, physiological and safety needs are the base of the pyramid and once they are unsatisfied, the whole pyramid seems unstable and will probably collapsearousing nerve, anxiety and irrational behaviors. Under this circumstance, people feel that their lives are put under great threat and survival become a big problem, which drive them to do all they could to support themselves with a basic living system. Such powerful and primitive instincts are actually subliminal thoughts that would control people's mind, which also push all other higher-level issues into secondary importance. On the other hand, since the radiation cannot be seen or touched, people do not know whether they are under exposure unless using prospecting instruments (Golay, M.W. 2001). As a result, people have nothing to do to 
keep away from radiation and it is easy to make people consider that the contaminated air, water and food are long-time physiological threats to daily life though technically the radiation is not serious and can't bring any physical and physiological damages.

Cognitive theory could also be used in explaining the panic to nuclear accident (Gray, 1998). It is known that new fear-related information will evoke the fear memory and the brain will integrate them into it. As long as the schema of fear is activated, people will use coping pattern they learned in the past to deal with the new situation. For the general public, nuclear energy has a notorious reputation and has already taken root in the fear structure. Disasters like the nuclear bomb and Chernobyl accident left horrible impressions and any cue related to these catastrophes will recall them. In other words, what the public fear is not only the new situation alone, but the combination of the new accident and previous memories of disasters. For instance, although the Fukushima accident has little similarity with Chernobyl, people treat it as seriously as Chernobyl because former accidents are in the deep mind and people retrieve them almost unconsciously.

This fact above mentioned could also be explained with the representativeness, availability and anchoring/adjusting heuristics employed in cognitive theory. Firstly, the representativeness heuristic focuses on similarity and resemblances and people with this mind tend to compare the new stimulus with prior events in memory and see if the new one resembles the old one and can represent it. In Fukushima accident, most people considered the chemical explosion of the plant represents the nuclear burst because the scene of chemical explosion is similar to the atomic burst-fire, smoke, slam-bang and all imaginary factors in an explosion are equipped. As a result, without knowing the fact, people consider there is a nuclear burst and the damage to their daily life is huge, which is a misunderstanding. Secondly, the availability heuristic refers to that people assess an event with instances or occurrences in the mind directly and if instances of a certain event can be recalled, people tend to believe that the new event is just like the old instances. The Hiroshima nuclear bomb and Chernobyl nuclear accident still dwell firmly in people's memory and make people believe that all the nuclear accidents are as serious as them. Last but not least, anchoring/adjusting heuristics also plays a very important role. People like to estimate by adjusting from an initial value and first impressions are most lasting, which can bias people's evaluation of an incident. For instance, the Hiroshima nuclear bomb brought more than 100 thousand deaths and injuries while rumor said that the Chernobyl made more than 40 million victims affected. Therefore, people anticipate that a nuclear accident anchors a massive casualty at the very first beginning. Although other nuclear accident is far less severe than them, a high anchoring number make people overvalue the consequence (Chen et al. 2012).

In a word, with the experience of former serious nuclear accidents in mind, public believe that any nuclear accident may harm one's health severely and the peace and harmony of society will also be broken. On the other hand, unpredictable and chaos world also are imagined after nuclear accident due to the memory of nuclear blasting in Hiroshima and Nagasaki. As a result, people will overrate the severity of nuclear accidents and overvalue the consequence under biased perception (Koerner, 2014). Furthermore, the pessimistic prediction can bring anxiety and anxiety brings more negative thoughts, just like a vicious circle often observed in risk science.

\subsection{The analysis of irrational behaviors in nuclear accident with psychoanalytic theory}

The public irrational behavior is an essential part in the study of crisis communication and the psychoanalytic theory could be employed in this issue. Sigmund Freud proposed a series of psychoanalytic theories and the production of ego defense mechanisms when the conflict happens among identification (ID), ego and superego are the main part of his theoretical framework(Peng, 2004). Anxiety breaks out when conflicts emerge and ego will employ defense mechanisms to protect the individual if the anxiety becomes overwhelming. Defense mechanisms transfer the ID impulses to acceptable forms to defend the conflicts, thus helping one to maintain in a favorable self-image and social acceptance. In other words, the defense mechanism is a method that people protect themselves when in a threating environment. No matter this method is really effective or not, it makes sense as long as people think it is helpful. That is because people like to deal with crisis actively other than passively enduring them and it actually help people stay in a positive $\operatorname{mood}($ Poumadère et al. 2013).

Displacement is such a typical kind of defense mechanism that discharges nervous feelings on nonthreatening target, which separates emotion from the original impulse in order to avoid dealing directly with what is harmful. For instance, there is salt-buying panic in China during the period of Fukushima nuclear accident and with the defense mechanismdisplacement, this phenomenon is easy to understand. Radioactive substance could not even be seen or felt, which makes people unable to take any efforts to deal with them. Therefore, people need a more concrete thing to outlet their strong emotion. Salt is then chosen as a displacement - it is common, necessary, easy to 
obtain and furthermore, it sounds like having a strong relationship with radiation protection because it contains iodine, which heard just like the iodine plates provided by government for avoiding the radioactive iodine I-131 gather in thyroid. With the above information, people establish the logical relationship between salt and radiation protection. On the other hand, rumors about sea water being polluted and salt with radioactive substance spread out to market in the future also make people begin to hoarding a great amount of salt in order to ensure the supply of daily salt in the family. Through such action, anxiety is released and people feel more comfortable with the situation. Salt works as a displacement of the nuclear panic and buying salt means avoiding nuclear matters under this defense mechanism. Fortunately, Chinese government release out salt stored in the stock to meet market needs and such method releases the anxiety of people and furthermore safeguards the social stability to a great extent.

In this sense, the irrational behavior is the reflection of public nervous condition and could not be prohibited by the government. What the government should pay attention to is the reason and origin of the public irrational behavior and providing appropriate response methods, which means trying to properly channel public sentiments.

\section{Effective Risk and Crisis Communication about Nuclear Accident}

With the statements mentioned above, the detail suggestions of crisis communication about nuclear accident are given as follow:

(1) Giving proper and instant information. Basic information of the crisis needs to be launched. If there is a nuclear accident, the basic 5Ws (what, when, where, who, how) need to be launched at the very first time(Shao, 2008). Then, the solutions such as evacuation notification, necessary actions to reduce the harm of nuclear radiation, symptoms and medical treatments or prohibition of eating local food in the radiation area need to be informed. It should be informed to the victims as early as possible and then to the potential victims to help them evacuate. Due to the difficulty and longtime of solving plant explosion, crisis communication has to last even longer. Post crisis stage also plays important role in the whole process. Especially when the condition of plant is being taken good care of, the focus of public will tend to criticize and question the cause of the crisis, who should take the blame and responsibility and who should pay for the lost. During this stage, a press conference is very necessary to explain these questions and even a letter of apology on newspaper can be needed if the organization wants to show sincere regret.

(2) Improving the interactions between nuclear power and public. The reason why public is fear of nuclear power is that they never get access to it except those who live near the nuclear plant. As long as they get familiar with nuclear power, they will have a better understanding of it. Therefore, it is helpful to invite public to visit the nuclear plants and companies in order to shorten the physical and mental distance between public and nuclear power. At the same time, nuclear scientists and professional staffs should make speech on their personal experience with nuclear power to help public eliminate the panic of nuclear power. Meanwhile, the government should take the leading position in eliminating panic and do their best to convince the safety to public (Shen et al 2013). What the public care most is the attitude of government and in this sense, the demonstration actions of government are better than any other homiletic sentences.

(3) Making experts closer to public. Experts are rich in professional knowledge in this field compared to the lay people who do not have an adequate background. It has been found that due to the difference in role and knowledge, experts develop distinct cognition pattern when evaluate risks. With an overall view, experts will have a solid consideration and think more thoroughly whereas the general public's incomplete thoughts may lead to irrationality. The communication between experts and the public is not on the same level, and furthermore, they even do not reach agreements on several basic concepts. Therefore, to make the public accept professional advice, narrowing the gap in cognition and common premise should be set. The nonspecialist descriptions and explanations are necessary in the experts' talk about nuclear accident and furthermore, the gentle mode, fluent expression and creditable sentences are also easy to be accepted by the public. It is not wise to invite a pedant to give comments on nuclear accident with lots of technical terms but with poor presentation skills through social media, which has been proved by amount of instances.

(4) The government should communicate with public in modest manners. The communication between the public and government is an interactive process, but in fact, they are not equal in status. The public always acts as the passive side and only receives information 
from the government. While the government always takes the DAD pattern (decide, announce, defend) to the public. Whether the government can treat the public as "partners" is vital to the efficacy and validity of communication. Any policy of obscurantism will definitely fail unless the government can show enough respect to the public or gain trust and support from the community. The government should believe that a majority of people have the ability to understand scientific knowledge if the manner is appropriate. Efforts should be made to build up a multiple communication network where authority, experts, media and public can be integrated organically and have a good interaction.

One thing needs to mention here is that when refer to crisis communication, people will always connect it with mass communication channels such as newspaper, radio and TV programs, etc. (Vaillant, 1997). However, we also have public communication and group communication (Xie et al. 2003). Though mass communication is easier to be used by organizations and government, the effect of public communication and group communication cannot be ignored. If not, they can serve as good methods for rumors spreading. Also, a recent phenomenon in China needs to be paid special attention as well. That is the rise of opinion leaders on Weibo and Wechat. Their existence forms the two-step flow of communication, which means the information comes from mass media, first goes to the opinion leader and then it flows to the flowers of opinion leader. If the official account of the organization posts an explanation of plant explosion on Weibo but one of the opinion leader shares it with a comment of "untrue excuse" then many of his or her followers will follow his opinion even though they do not check whether it is true or not. This phenomenon may have great influence on the effect of crisis communication thus can be a main topic of our study to work on(Esperanza et al. 2012.).

We study the characteristics of information spreading with information tracing methods, which is a popular way to study the communication in the sense of big data analysis. The data is collected from the preset reprinting counter embedded in the website and if this news is reprint by other website or weibo, the counter point will be produced, whose trajectories could also be shown. The data is processed with Ontospace software and the entropy and complexity could be obtained.
Fig.2 shows that the spreading of information "Fukushima accident have no influence to Chinese coastal fishery" in traditional websites and Weibo after Fukushima accident. The original point is the first launch of this information and other points means the reprinting by a secondary site. The connecting between two points represents a spreading channel. It is found that generally speaking, the times of information reprinting are no more than fifty in the websites but the reprinting times are more than one hundred in Weibo. On the other side, it is also shown that the cascade reprinting exists in the case of Weibo and the numbers of nodes are more than ten, compared with the case of traditional websites. With Detailed statistical analysis, the entropy and complexity of these two net diagrams are given. The entropy and complexity are the scale of the spreading effect in communication and if the value of a spreading mode is larger than other modes, it means this mode is better in the sense of communication and feasible for the public to obtain. From Table 1, it is obvious that the effect of Weibo is better than traditional websites, which demonstrate that using new media is necessary and essential for the future communication of nuclear accident.

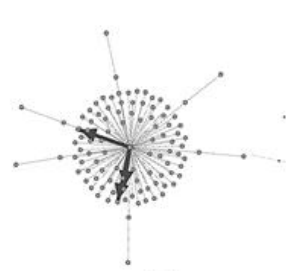

(a)

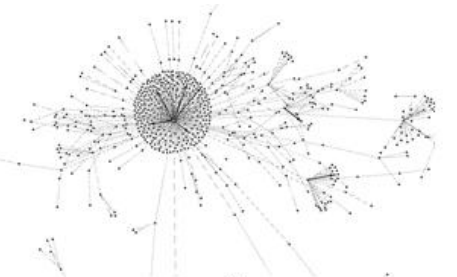

(b)
Fig.2. The spreading channel of same information in traditional website (a) and Weibo (b).

Table 1 The entropy and complexity of Fig.2 (a) and (b), the value of Fig.2 (b)'s is normalized to 100

\begin{tabular}{|c|c|c|}
\hline & Traditional websites & Weibo \\
\hline Entropy & 59 & 100 \\
\hline Complexity & 52 & 100 \\
\hline
\end{tabular}

\section{Conclusion}

In this article, we reviewed the cases of risk and crisis communication after three famous nuclear accidents (Chernobyl, Three Mile Island and Fukushima) and studied the public risk and crisis communication after nuclear accident with psychological methods. It is shown that the panic to nuclear accident is due to the worry of inaccessibility to food, air, water and other 
basic physiological needs as well as the uncertainty of safety, so it is not easy to find path to eliminate public aversion about it. To the irrational behaviors of public, it is necessary to give channel to release these modes of people. According to the results, the government and experts who are in charge of risk and crisis communication should think in the public's shoes and concern what the public concern and try to explain in a clear and easy way to make it understandable. Notably, the new media such as Wechat and Microblog play very important role in the risk and crisis communication about nuclear accident nowadays, which shows much larger spreading range than traditional media. On the other hand, improving the public acceptance to nuclear energy is also helpful in the future risk and crisis communication, which is another way help to improve the communication work.

\section{Acknowledgements}

This work is supported by the independent research and development fund of Tsinghua University (Grant No. 20121087948).

\section{References}

Y. Chen, The Nature Event's Probabilistic Risk Assessment of Nuclear Power Plants with Improvements, Journal of Risk Analysis and Crisis Response. 2(2) (2012) 139-145.

Y. Chen, et al, The Nature Event's Probabilistic Risk Assessment of Nuclear Power Plants with Improvements, Journal of Risk Analysis and Crisis Response. 2(2) (2012) 139-145.

V.T. Covello, et al, Risk communication, the west Nile virus epidemic, and bioterrorism: Responding to the communication challenges posed by the intentional or unintentional release of a pathogen in an urban setting, Journal of Urban Health: Bulletin of the New York Academy of Medicine. 78(2) (2001) 382-391.

X.W. Ding, et al, A Two-Step Water-Management Approach for Nuclear Power Plants in Inland China, Journal of Risk Analysis and Crisis Response. 4(4) (2014) 184-202.

L. V. Esperanza, et al, Volcanic Risk Perception, Locus of Control, Stress and Coping Responses of People Living Near the Popocatépetl Volcano in Mexico, Journal of Risk Analysis and Crisis Response. 2(1) (2012) 3-12.

E.B. Foa, et al, Emotional Processing of Fear: Exposure to Corrective Information, Psychological Bulletin 99(1) (1986) 20-35.

R.J. Gerrig, et al, Psychology and Life (18th edition) (Allyn \& Bacon, Boston, MA, 2007).
M.W. Golay, On social acceptance of nuclear power. New energy technologies: A policy framework for micronuclear technology. (2001)

P. Gray, Improving EMF risk communication and management: The need for analysis and deliberation, EMF risk perception and communication, in Proceedings International Seminar on EMF Risk Perception and Communication, (Ottawa, Ontario, 1998) pp. 51-68.

R.C. Hoetzlein, Visual Communication in Times of Crisis: The Fukushima Nuclear Accident, Leonardo. 45(2) (2012)113-118

C. Koerner, Media, fear, and nuclear energy: A case study, The Social Science Journal. 51 (2014) 240-249.

A.H. Maslow, A theory of human motivation, Psychological Review. 50(4) (1943) 370-396.

H. Otway, et al, Risk communication in Europe after Chernobyl: A media analysis of seven countries, Organization Environment. 2(1988) 3-15.

D. Peng, General Psychology, (Beijing Normal University Press, Beijing, 2004).

M. Poumadère, et al, Risk Assessment of Radio Frequencies and Public Information, Journal of Risk Analysis and Crisis Response. 3(1) (2013) 3-12.

$\mathrm{X}$. Shao, Experimental study of attentional bias to threat information in trait anxious individuals. Ph.D. thesis (Tianjin Normal University, Tianjin, 2008)

K.H. Shen, et al. The study of panic to nuclear energy on psychological and sociological issues, ICONE21, (Chengdu, China, 2013)

A. Skarlatidou, et al, What Do Lay People Want to Know about the Disposal of Nuclear Waste? A Mental Model Approach to the Design and Development of an Online Risk Communication, Risk Analysis. 32(9) (2012)14961511.

P. Tanja, et al, Is knowledge important? Empirical research on nuclear risk communication in tow countries, Health Physics Society. 102(6) (2012) 614-625.

P. Tanja, Radiation risk perception: a discrepancy between the experts and the general population, Journal of Environmental Radioactivity. 133 (2014) 86-91.

G.E. Vaillant, Adaptation to life (Boston, MA, 1997).

X. Xie, et al, Risk Communication and Public Rationality, Advances in Psychological Science. 11(4) (2003) 375-81.

D.J. Zeigler, \& J.H. Johnson, Information Planning and the Geographical Context of Radiological Emergency Management, The Royal Geographical Society. 14(3) (1989) 350-363. 